\title{
Ethical and legal issues of left against medical advice disharges
}

\author{
Dr. Tanka Prasad Bohara
}

\author{
Assistant Professor \\ Department of Surgery, Kathmandu Medical College Teaching Hospital \\ Correspondence: tankaprasad.bohara@gmail.com
}

Left against medical advice (LAMA) is one of the situations we face as a healthcare provider. It is also called discharge against medical advice (DAMA), self-discharge or leave before their visit (or admission) is complete (LBVC)(1-3) But is it ethical and legal to send patient against medical advice (AMA) especially in a situation where a patient cannot give consent for him or herself particularly in a case of a critical patient coming to an emergency department and patient admitted at intensive care units where denying the treatment may lead to the death of the patient?

Though the study to look into LAMA discharges, in particular, are not available at present in Nepal, on searching PubMed and google scholar, various studied have data on LAMA discharge ranging from $4 \%$ to $15 \%$ in critically ill patients. (4-9) Retrospective studies from abroad have identified younger age, Medicaid or no insurance, male sex, and current or a history of substance or alcohol abuse as predictors of LAMA discharges.(1) Though the studies regarding causes of LAMA discharges are lacking from our country, financial exhaustions is one of the commonest cause cited by patients relatives. After few days of intensive care unit treatment patient's family are usually financially exhausted because of lack of proper insurance and expensive treatment. Then the situation arises when a patient is potentially salvageable but the family members cannot actually support the treatment financially. Some of the patients leave AMA and probably eventually die of a potentially salvageable ailment if the treatment would have been continued.

When the patient competent enough to give consent does not want to continue treatment or refuses treatment, there is a less ethical problem because of patients right to decide for him or herself.(1) However it's still the duty of health care providers try to convince the patient to continue the treatment and also to record the process properly. But in the scenario described above where patient is not able to give consent for him or herself, are the family members authorized to give consent for not continuing the treatment which would potentially lead to the death of the patient? Can health care providers stop the treatment and allow AMA discharge based upon the consent given by family members? If we critically think the answer to above question may be no. Because it is healthcare provider's duty not to deny the treatment if patient or relatives cannot pay for emergency and life-saving condition. Another issue is the constitutional right of the patient to live and how other persons can decide for him. How can we be sure that the persons giving consent for the patient are protecting the best interest of the patient? It may be troublesome for the healthcare providers if the act of sending the patient AMA based on the consent signed by others in life death situation is challenged in a court.

We believe that once LAMA consent is signed by the patient or their relatives we and the hospital is not liable for the patient's fate and we don't have any further legal implication. But it's not true. There are instances where healthcare providers are sued even after leaving against medical advice with duly signed consent.(10) Devitt et al described four cases where the medical authorities and physicians were sued for malpractice even after the patient left AMA.(10) In all cases, defendant prevailed not because of LAMA consent but because of plaintiff's failure to prove negligence. They concluded that LAMA consent may not be sufficient to protect legal liabilities of health care providers. The signed consent may help but does not make healthcare providers immune from legal implications.(3)

Now the question arise what should be done in such situation where patient need treatment, family members want to take patient AMA due to various reasons? There should be proper guidelines regarding this sort of situation. National guidelines would be most appreciated if not hospital policy makers should make a guideline for their hospital on how to deal with these situations especially when finance is the reason for not continuing the treatment. A collective decision should be taken after proper assessment and prognostication of the patient by a 
team which should include treating physicians, patient's relatives who can properly understand the risks of not continuing the treatment and prognosis of the disease and independent witness along with a legal officer and hospital administrator. Hospital administrators and the hospital legal officer should always be aware and involved in this situation because they are in decision-making process of supporting finances if treatment is to be continued in potentially salvageable patients when the family cannot financially support the treatment. They should have a policy of funding the treatment of such patients. However in the situation is different when healthcare providers are not fully convinced that the relatives are acting in the best interest of the patient, they can approach a court for involuntary or compulsory admission to hospital.(10) But again who would take the financial burden of the treatment. The State should ideally be responsible for these patients but the social responsibility of the health institutes cannot be undermined as well.

\section{References}

1. Alfandre DJ. "I'm going home": discharges against medical advice. Mayo Clin Proc. 2009 Mar;84(3):255-60.

2. Clark MA, Abbott JT, Adyanthaya T. Ethics seminars: a best-practice approach to navigating the againstmedical-advice discharge. Acad Emerg Med. 2014 Sep;21(9):1050-7.

3. Fadare JO, Jemilohun AC. Discharge against medical advice: Ethico-legal implications from an African perspective. South African J Bioeth Law. 2012 Nov 23;5(2):98-101.
4. Chalise PR, Shrestha S, Sherpa K, Nepal U, Bhattachan CL, Bhattacharya SK. Epidemiological and bacteriological profile of burn patients at Nepal Medical College Teaching Hospital. Nepal Med Coll J. 2008 Dec;10(4):233-7.

5. Koirala S, Ghimire A, Sharma A, Bhattarai B. ICU admission and outcomes in a community-based tertiary care hospital: an audit of one year. Heal Renaiss. 2011 Jul 4;9(2):83-7.

6. Sharma NR. Outcome of intubated post-surgical cases in intensive care unit in Tribhuvan university teaching hospital, Nepal. J Inst Med. 2005;27(3):29-30.

7. Thapa LJ, Twayana R, Shilpakar R, Ghimire M, Shrestha A, Sapkota S, et al. Clinical profile and outcome of acute encephalitis syndrome (AES) patients treated in College of Medical Sciences-Teaching Hospital. J Coll Med Sci. 2014 Jan 21;9(2):31-7.

8. Chhetri PK, Manandhar DN, Pahari LR, Chhetri SS, Chaudhary SK. Acute renal failure in Nepal Medical College Teaching Hospital. Nepal Med Coll J. 2008 Jun;10(2):132-5.

9. Khakurel S, Satyal PR, Agrawal RK, Chhetri PK, Hada R. Acute Renal Failure in a Tertiary Care Center in Nepal. J Nepal Med Assoc. 2005 Apr 1;44(158):32-5.

10. Devitt PJ, Devitt AC, Dewan M. An examination of whether discharging patients against medical advice protects physicians from malpractice charges. Psychiatr Serv. 2000 Jul;51(7):899-902. 